\title{
Built leadership: women administrators in architectural education
}

\author{
Margaret Dale Woosnam, Ph.D. \\ Texas A\&M University, College Station, Texas
}

\begin{abstract}
Of the 114 accredited architecture programs within colleges and universities across America, only 18 (or $16 \%$ ) employed females at the highest administrative positions as deans, directors, chairs, or heads at the time this study was conducted. Despite this statistic, nearly $50 \%$ of all graduates from architecture programs are female. Little is known about women administrators in architectural education, perhaps because of the fact that there are so few.

The central question that guided this research study is as follows: What personal and professional factors characterize 10 women employed as administrators in nationally accredited architecture programs, departments, schools, and colleges in American institutions of higher education? Additionally, this study identified the women's career paths, and obstacles they overcame and sacrifices they made in order to advance in their careers.

The qualitative case study tradition was employed for this study. Ten women administrators of accredited architecture programs, departments, schools, and colleges within American institutions of higher education participated in the study. Interviews, documents, and observations were collected and included in the data analysis.

While feminist leadership theories were used as a lens and guided the current research, themes emerged from the study that point toward a potentially new, emerging theoretical construct. This emerging construct requires that pioneering female leaders in male-dominated fields be characterized differently than female leaders in other contexts. Specifically, the conclusions drawn from this study require characterizing pioneering female leaders in male-dominated fields as built leaders or leaders who have systematically developed professionally as a result of unwavering ambition but who employ a post-heroic style of leadership. In other words, these women fought their way to the top, but once there, use an up, down, and across hierarchical leadership style.
\end{abstract}

Conference theme: Human context: social, cultural, and economic studies

Keywords: women, architectural education, education administration, post-heroic leadership

\section{INTRODUCTION}

Of the 114 accredited architecture programs, departments, schools, and colleges in institutions of higher education across the country, only 18 (or 16\%) had females filling the highest administrative positions as deans, directors, chairs, or heads at the time this study was conducted (National Architectural Accrediting Board [NAAB], 2006). Currently, approximately $50 \%$ of all graduates from architecture programs are females (Deutschle, 2003; NAAB, 2006; National Center for Education Statistics, 2005). Little is known about female administrators in architectural education, perhaps due to the fact that so few females hold these positions. Further, because research regarding females in these positions is limited, other females who may wish to pursue similar careers have little to look to for career guidance.

\subsection{Study purpose}

The purpose of this study was to uncover characteristics common to 10 women administrators in accredited architecture programs, departments, schools, and colleges.

\subsection{Research questions}

The central question that guided this research study is as follows: What personal and professional factors characterize females employed as administrators in nationally accredited architecture programs, departments, schools, and colleges in American institutions of higher education? The following secondary questions also guided the study:

1. What career paths did these women embark upon that led them to their positions, and how have their career paths impacted them professionally and personally?

2. What obstacles do these women believe that they overcame in their careers to achieve their positions, and how did the obstacles impact them?

3. What personal sacrifices, if any, did these women make in order to achieve their positions, and how 
did these sacrifices impact them?

4. What are the women responsible for in their administrative position and how do they lead?

\section{REVIEW OF LITERATURE}

This study drew from existing leadership theories including gender-related and feminine leadership theories. Further, because this study covered an examination of female administrators in maledominated fields within American institutions of higher education, an examination of literature on females within institutions of higher education is included.

\subsection{Females in male-dominated fields}

The topic of females entering male-dominated fields is one that has been widely researched since the 1970s, the time when females began entering institutions of higher education and the work force in marked numbers (Cohen, 1998). However, much of the existing research focused on females in particular

fields, including engineering and medicine in the United States, and the priesthood within the United Kingdom (Aldridge, 1994; Bagilhole, 2003; Rose, 1996). The majority of the research on females in architecture dates from the late 1980s and early 1990s (Dietsch, 1991; Landecker, 1991; Solomon, 1991).

Nevertheless, research regarding female faculty members in the male-dominated field of architecture has been largely ignored, with only a few exceptions (Anthony, 2001; Gregory, 2006; Groat \& Ahrentzen, 1997). Currently, approximately half of the student population in architecture programs nationwide is female; however, the attrition rate of females after graduation is high, perpetuating the male-dominance in the field (Gregory, 2006).

Research has attempted to uncover motivating factors and experiences of females who pursue careers in male-dominated fields. In a book entitled Gender Roles through the Life Span (Stevenson, 1994), Frieze and Olson (1994) contributed a chapter that addressed research conducted on the values that males and females assign to occupational fields. Frieze and Olson (1994) noted that the feminine professions were thought of as those that would allow the workers to help others, whereas the masculine professions were thought of as those that would allow the workers to demonstrate capability. Additionally, Frieze and Olson (1994) found that individuals' values strongly affected their occupational choice. Specifically, females in maledominated fields placed value on gaining professional recognition, demonstrating capability, and making more money than did females in non-male-dominated fields.

Peng and Jaffe (1979) contributed one of the seminal pieces regarding females entering male-dominated fields of study in college. The authors noted that females in male-dominated fields tended to score higher on a work scale and lower on the community and family scales when compared to females in fields that are not male-dominated. This finding indicated that females in male-dominated fields of study were required to be more career-focused and less familyfocused.

More recently, Steele, James, and Barnett (2002) examined the perceptions of female undergraduate students enrolled in male-dominated academic areas. Specifically, Steele, James, and Barnett (2002) focused on females in the areas of math, science, and engineering because, as they noted, fewer females earn undergraduate degrees in these fields. They found that females in these male-dominated areas of study: (1) experienced higher levels of gender-related discrimination, (2) anticipated higher levels of genderrelated discrimination, and (3) felt threatened by gender stereotypes. Additionally, the researchers found that females in these areas of study were more likely to consider changing their major before they graduated than were males or females in female-dominated fields of study.

Bagilhole (2003) addressed the dynamic shift in hegemony within the Church of England that occurred in 1994, when the diocese allowed females to become ordained priests in the United Kingdom. Bagilhole asserted that the first few generations of females who entered male-dominated professions were "pioneers" (p. 361). She further contended that these females were "change agents" (p.361) of the organizational culture and structure in the Church of England.

Employing focus groups, Chu (2005) found that female engineering students experienced great difficulty in interacting professionally with their male cohort while remaining feminine in their actions. Further, she found that females in the engineering program were much more likely to consider a change of major than men because of the interaction difficulty. Chu (2005) drew upon the work of Brainard, Metz, and Gillmore (1999) and Seymour and Hewitt (1997) who examined the lowered confidence levels that females in maledominated fields of study exhibited when compared to the males in their fields of study. The researchers found the lowered confidence levels, regardless of the grades the females had earned in their coursework. The researchers concluded that the females' lowered confidence had little to do with their classroom performance, but rather resulted from discouragement by professors, the workload, and the weed-out processes associated with male-dominated fields, including engineering and architecture.

Researchers who investigated entrepreneurs found that, in general, entrepreneurship is considered to be male-dominated (Chaganti, 1986). Additionally, researchers suggested that the majority of female entrepreneurs do not enter male-dominated fields (Moore, 1990; Scherer, Brodzinski, \& Wiebe, 1990).

Several researchers investigated the utility of androgynous physical characteristics and behaviors by females in male-dominated fields. The majority of the research was completed in the 1980s. Specifically, Jagacinski (1987) examined the sex-typed traits of male and female engineers, and found that physically and behaviorally androgynous females reported higher levels of work-related responsibility, involvement in professional activities, and overall satisfaction when 
compared to female engineers who were not androgynous. Androgynous female engineers were also found to earn a higher salary than female engineers who were not androgynous. Lemkau (1983) examined the personal characteristics of females in male-dominated professions and non-male-dominated professions. Lemkau found that females in maledominated professions were "tough-minded" and "assertive" (Lemkau, 1983, p.144), and exhibited characteristics that are associated with behaviorally androgynous females and masculine males. Rudman and Glick (2001) found that physically androgynous females were less likely to be discriminated against in performance-driven institutions.

\subsection{Females in architecture}

Although females have been practicing architecture for over 100 years (Almanac, 2004), females had not entered the profession in large numbers until the last several decades (Deutschle, 2003). The existing literature regarding females in architecture focused on females in the architectural profession. Little emphasis has been placed on females in architectural education and administration within institutions of higher education.

Solomon (1991) identified a shift in the proportions of females within corporate architectural firms. Solomon published data collected from a survey of 20 members of the AIA Large Firm Roundtable. According to these data, females were not reaching the top ranks in the profession (i.e., at the time of her study, $2 \%$ held principal positions). Solomon interviewed males and females in leading architectural firms in order to learn more about this phenomenon. She found that many males believed that females were not reaching the top ranks because the number of qualified females in the architectural profession was limited. The percent of female principals rose from $2 \%$ in 1991 to $21 \%$ in 2006 (American Institute of Architects, 2006).

Anthony (2001) completed survey research that indicated females in architectural practices experienced roadblocks and obstacles to advancement. Anthony also found that females in the field found the tasks of job interviewing, interning, and completing the licensing exam particularly intimidating. Additionally, she found that females in the profession often do not stay in the profession due to discrimination and harassment, pay inequity, and familial responsibilities.

Deutschle (2003) wrote about issues females face in the architectural profession. Her news report stated that nearly $50 \%$ of all American college students that graduate from university architecture programs are female, while only $13 \%$ of licensed practicing professionals working at AIA-member organizations are female. Notably, Deutschle's article was not published in a journal, but rather a daily newspaper, which indicated that this issue was noteworthy to the mainstream.

Landecker (1991) was one of the first to research the gender disparity in the architectural professoriate. In her article entitled "Why aren't more females teaching architecture," Landecker compared nationwide data on faculty in institutions of higher education with data on males and females in architectural faculties. She found that full-time male professors of architecture made up $19.5 \%$ of all faculty nationwide, while full-time female professors of architecture made up only $0.8 \%$. Tenured male professors of architecture made up 33\% of all architecture faculty nationwide, while tenured females made up only $2.8 \%$. Landecker (1991) acknowledged statistics disseminated by the Association of Collegiate Schools of Architecture (ACSA) published in 1990 that reported an increase in the number of females in graduate programs of architecture. She interviewed several female professors of architecture and published their opinions regarding why females were not teaching architecture. She found that these female professors believed that, until females are promoted to top-level positions in higher education, the number of female faculty in architectural education will continue to wax and wane.

The females interviewed in Landecker's study stated that many females were not hired when qualified. Additionally, when females were hired to teach, they were given the marginal assignments, including teaching the 'soft' courses such as design, history, and planning, and they were required to serve on more committees and complete more service projects than their male counterparts. The females interviewed believed that, when females occupy the administrative positions in architectural education, female faculty will be awarded the more technical courses and will not be burdened with the extra service assignments.

Groat and Ahrentzen (1997) wrote about female faculty in architecture and addressed Landecker's (1991) idea of marginality. However, Groat and Ahrentzen did not suggest ways to overcome this marginality, but rather, suggested ways to use it as a tool. They suggested that these females use their service requirements and soft courses to challenge the "ideals of liberal education" ( $p$. 274 ) and to forge "interdisciplinary connections" (p. 275) among other things.

\subsection{Females in academic positions}

Researchers found that females still face gender discrimination in institutions of higher education. This gender discrimination has manifested in various ways, including hiring and tenure discrimination, pay inequity, and pregnancy discrimination (Kaplin \& Lee, 1995; Smallwood, 2001; Wilson, 2004).

Although in recent years, institutions of higher education have undergone significant diversification at most levels, the administrative positions have remained White-male-dominated (AAUW, 2004). As addressed in another section of this literature review, researchers indicated that females who achieved upper-level positions oftentimes exhibited more physically and behaviorally androgynous characteristics than their female colleagues (Jagacinski, 1987; Lemkau, 1983), and made more personal sacrifices than their male colleagues (AAUW, 2004; Williams, 2004). Additionally, females who achieved upper-level positions were subject to gender bias (Dreher, 2003; Eagly \& 
Johannesen-Schmidt, 2001; Ridgeway, 2001; Rudman \& Glick, 2001).

\subsection{Feminine leadership}

Scholars of feminine leadership theories claim different perspectives regarding females in leadership. Overall, researchers found that feminine leaders focus on relationships and participatory practices.

Feminine Leadership

Fletcher (2004) addressed the mostly feminine "post-heroic" form of leadership (p. 647). Fletcher (2004) found that feminine leaders employ post-heroic (or non-traditional) leadership that focuses on collaboration and social networking. Three specific characteristics that define this style of leadership are:

1) leadership as practice: shared and distributed, in which leaders rely on skill sets of enabling, supporting, facilitating and collective achievement, social networks, teamwork, shared accountability, collaboration, and blurred lines between the leader and the follower; 2) leadership as social process: interactions, in which leaders portray a dynamic, multidirectional, collective, egalitarian, mutual, less hierarchical style and are open to being led by others by being less competitive with a fluid boundary between self and other; and 3) leadership as learning: outcomes, in which leaders seek to establish mutual learning, collective understanding, and positive action in order to foster cocreated and implemented collective learning. This final aspect of post-heroic leadership also relies on emotional intelligence, including self-awareness, empathy, vulnerability, and an openness to learning. In sum, Fletcher (2004) defined post-heroic leadership as distributed leadership; "up, down, and across" the hierarchy (p.650).

Jablonski (2000, p. 245) found that female university presidents employed "participatory" leadership styles. Jablonski (2000) indicated that the female presidents emphasized collaboration, communication, and shared decision-making.

Other researchers of gender-related studies identified that feminine leaders focused on relationships and participatory processes. Burstyn (1980), DiBrito, Carpenter, and DiBrito (1986), Funk (1988), Gilligan (1982), Miller (1986), and Morgan (1986) found that females in education emphasized communication and teamwork.

\section{RESEARCH PROCEDURES}

The research method used for the current study was the qualitative case study method. More specifically, the research method for this research consisted of a collective case study. Yin (1989, p. 23) suggested using the case study method when the research requires an investigation into a "contemporary phenomenon within its real-life context, when the boundaries between phenomenon and context are not clearly evident, and in which multiple sources of evidence are used." Leedy \& Ormrod (1997) indicated that case studies are useful when the researcher aims to learn more about a little known topic. Leedy and
Ormrod (1997, p.149) also suggested using a collective case study method in order to "make comparisons." Comparisons were important in this study because they served to inform the researcher of the women's common characteristics.

This study employed the narrative research strategy defined by Creswell (2003) as "a form of inquiry in which the researcher studies the lives of individuals and asks one or more individuals to provide stories about their lives" (p. 15). Creswell (2003) recommended that these stories be re-told by the researcher in a "narrative chronology" (p.15). Because this study was designed to identify 10 women's career paths, obstacles they overcame, personal sacrifices they made, and their current leadership, their stories as they reflected on their journeys to leadership were a focus of this study. After the stories were gathered and then retold by the researcher, an analysis was conducted in order to identify characteristics common to the women, which was the overarching purpose of the present research study.

\subsection{Data collection procedures}

The eight women who were geographically located farthest from the researcher (Clemson, South Carolina) were asked to participate in telephone interviews and the two women who were geographically located closest to the researcher were asked to participate in face-to-face interviews held at both of the administrators' campuses. Although two women initially agreed to participate in face-to-face interviews, one of the women participated in a telephone interview because of scheduling conflicts during the period of data collection. Therefore, only one face-to-face interview was conducted.

Prior to the interviews, an interview protocol was developed and was followed for each interview. The protocol consisted of broad, exploratory questions designed to uncover thick, rich descriptions of the factors that characterize these women. Emergent insights continually directed and redirected data collection. Consistent with the constant comparison analysis technique employed in this study, new interview questions manifested after each interview and interview questions that were deemed inappropriate were deleted.

Using the interview protocol developed a priori, the researcher asked direct questions. However, the participants were asked to share and were allowed to do so freely. Follow up questions or questions of clarity were asked. Each interview was audio-recorded. Occasionally, the researcher emailed additional followup questions to the participants in order to address details that were not discussed in the telephone interviews or in the face-to-face interview.

\subsection{Data analysis procedures}

Because qualitative research is interpretive research (Creswell, 1994) and because the researcher intended to obtain a thick, rich description (or a "complete, literal description of the entity being investigated," Merriam, 2001 , p. 29) for each case, the data were analyzed in 
tandem with the data collection, as specified by the constant comparison method (Creswell, 2003). The data analysis was based on "reduction" and "interpretation" (Marshall \& Rossman, 1989, p. 114); as each typed interview was transcribed, notes were made of any overall tone, underlying themes, or subjects that were repeated throughout the interview. After all of the interviews were transcribed, commonalities within the characterizing factors were identified, emerging themes were reviewed, and conclusions regarding the factors and themes were made from the data.

Because interview data represent unstructured data, the eight analysis steps recommended by Tesch (1990) were used to allow the researcher the ability to engage in a "systematic process of analyzing textual data" (Creswell, 1994, p. 155). Both within-case and crosscase analyses were performed, respectively. A qualitative software package, NVivo $7^{(}$, that assists with the organization and analysis of interview and observation data was used to aid the researcher in the data analysis.

Tesch's (1990) steps were followed for analyzing observational data (when available) and documents for each case. In general, the documents and observations were used to learn more about the women, but were also used to supplement, complement, and "triangulate" (Creswell, 2003, p. 196) the findings from the interview data. After these steps were completed for each case, the researcher compared the emergent themes from each case across all of the cases.

\subsection{Strategies for validating findings}

In order to ensure the "trustworthiness" of the findings from the study (Creswell, 2003, p. 196), the researcher employed strategies identified by Creswell as necessary in qualitative research. First, the researcher "triangulated" the data sources (Creswell, 2003, p. 196) by analyzing the various forms of data collected for the emergence of themes. The researcher employed the "member-check" strategy as suggested by Creswell (2003, p. 196), which allowed participants to ensure the accuracy of findings by reviewing and approving interview transcripts and generalizations made by the researcher.

\section{FINDINGS}

The themes resulting from a cross-case analysis of the data (interviews, documents, and observations) for all the cases are detailed. The cross-case analysis findings are organized and presented by the secondary research questions.

\subsection{Secondary research question one: Career paths}

Formative experiences. Early childhood experiences with and exposure to architecture was the theme that emerged from the analysis of the interview data regarding why each woman chose a career in architecture. One participant said:

In particular, I remember the luscious pencil drawings of Pennsylvania farmhouses that he was renovating on his desk. That was kind of appealing.

Education. Two themes emerged from the women's discussions of the institutions of higher education that they attended: prestige and minority. Most of the 10 women attended institutions of higher education that are considered prestigious in the United States. Six of the 10 women attended private, Ivy League institutions of higher education for at least one of their two degrees. Four of the six women who attended Ivy League schools did so for both of their degrees. Regarding minority, the women expressed the fact that they were one of few women on campus and particularly in the architecture courses. One participant recalled:

I went to Princeton University and they did not have female students there for too long when I arrived.... And then I majored in a field that had mostly male students. So in any given class, I might be the only female student or there might be one or two others.

Field experience. The pervasive theme regarding the women's practical experience before returning to academia is that the women are entrepreneurs, but are aware of the fact that they are in the minority as practice principals. One woman stated:

\begin{abstract}
Principals are one thing. But firms that are actually owned by women and the principal architects are women -- almost none.... There was a time there were some, but slowly and surely they have just been absorbed...I honestly believe that even the most aggressive, tenacious, women - there are so few people who can take the constant isolation and beating. It's sort of the Hilary Clinton syndrome. You are distinguished by being alone and that aloneness just beats you up.
\end{abstract}

The majority of the women worked in firms that valued females, but experienced gender-related discrimination. One participant stated, "I was being paid vastly less than all the men with the same degrees." She said that, in that firm, she experienced "the glass ceiling, discrimination, under pay, and sexual harassment." Another participant recalled that all of "the men were making more money than the women, regardless of experience or qualifications." She continued, saying, men "were promoted to project architect or project manager," females were "backroom horses."

Preparation and advancement. The women's responses regarding what best prepared them for their work in administration varied. The theme that emerged from the women's discussions regarding their preparation for administration reveals that they were prepared both by aspects within and outside of their own control. The majority of the women indicated that they chose careers in higher education due to their desire to teach or be a part of academia. Additionally, two of the 10 women had a mentor or professor in college suggest that they consider teaching. While the 
majority of the women indicated that they aspired to administration, none of them said that they were actively seeking administrative positions. Most of the women have held their positions for less than five years. Seven of the 10 women were the first females to hold their positions at their institutions; however, most of them indicated that their being the first was a nonissue.

Personal life. Most of the women were married or in a long-term romantic relationship at the time this study was conducted. Half of the women have children and most are not caregivers for a loved one. The women spoke of their inability to care for an aging or ailing loved one due to their relocation for their current positions and consider this a personal sacrifice.

Demographics. The majority of the women are White. Six of the 10 women reported that they are White. One of the 10 reported that she is Black. One of the 10 reported that she is of European decent. One of the 10 reported that she is Hispanic. One of the 10 reported that she is Latin American. The average age of the women is approximately 52 years old. The youngest of the administrators is 48. The oldest of the administrators is 59. Many of the women's experiences regarding their entry into the profession may be similar because they are approximately the same age.

\subsection{Secondary research question two: Past obstacles}

Professional discouragement. While the majority of the women were discouraged professionally, they spoke of instances in which they used the discouragement as motivation. One participant remembered experiencing blatant discrimination from a male professor in college.

I came out of it [meeting with her professor] not feeling like, 'Oh, change is impossible. Oh, I'm inferior.' I came out of it thinking, 'Oh, this guy [her professor] is a dinosaur. He's dying and about to retire. Clearly I can do this...there are still a few little societal quirks that have to work their way out.' So if anything, it kind of built my confidence.

Pernicious behavior. The theme that emerged from the women's discussions regarding the pernicious behavior they faced is that the women expected this type of behavior and did not allow it to stifle them professionally. One woman recalled experiencing unconcealed disdain for her as a female administrator by members of the faculty in her department.

They did everything short of literally trying to kill me. They didn't actually do that, but everything else. They would devote 20 minutes at every faculty meeting to just screaming at me...these old guys with the veins popping out of their forehead. [I was] thinking, "You're going to have an aneurism right in front of me?"

Additionally, the women who experienced this type of behavior also indicated that this behavior was inevitable because of the prevalent gender-related issues or the academic undercurrents of competition.

\subsection{Secondary research question three: Personal sacrifices}

The pervasive theme that emerged from the 10 women administrator's discussions of the personal sacrifices that they made in order to achieve their current positions is that they sacrificed time with family for their careers. Seven of the 10 women indicated that they felt they made personal sacrifices in order to achieve professional advancement. Six of those seven discussed a sacrifice pertaining to family.

\subsection{Secondary research question four: Current responsibilities and leadership styles}

Regarding the women's current work responsibilities, the women are often overwhelmed by work, but are conscience of and sensitive to the human aspects of work and rely on social networks in their leadership. The women discussed their styles of handling conflict and conflict resolution and the majority indicated that they prefer to act as mediators, but only when intervention is absolutely required.

Regarding the women's interactions with their faculty, the majority of the women described their interactions as collegial. Additionally, many of the women described themselves as "in the trenches" with their faculty, as they also still teach courses, thus blurring the lines of leader (administrator) and follower (faculty).

\section{DISCUSSION AND RECOMMENDATIONS}

The 10 women who administrate in accredited architecture programs, departments, schools, and colleges within American institutions of higher education are built leaders, or leaders who have systematically developed professionally as a result of pioneering the field of architectural administration for females, but also by consciously using negative experiences and discouragement to fortify their drive, and by choosing to sacrifice aspects of their personal lives to advance their careers.

In addition to the obstacles the women faced because of the gender imbalance in the institutions of higher education they attended, the women faced similar obstacles once they entered the architecture profession. The majority of the women discussed hardships they faced due to the organizational and societal culture of the architectural firms in which they practiced soon after their graduation. The women also indicated that appearing professional was important to them, however, they desired to remain true to themselves in their appearances, behaviors, and priorities. Existing literature addressed some of the discrimination that females in architecture face (Anthony, 2001; Deutschle, 2003; Solomon, 1991). The current study supports the existing literature that indicated that females in the field of architecture and in institutions of higher education battled gender discrimination, pay inequity, and sexual harassment 
(Anthony, 2001; Deutschle, 2003; Kaplin \& Lee, 1995; Smallwood, 2001; Solomon, 1991; Williams, 2004). Not only did the women in this study overcome the hardships they faced while working in architectural practices that were male-dominated, the majority of the women said that they currently own or owned architectural practices. Entrepreneurship in general is considered to be male-dominated (Chaganti, 1986), and researchers of existing studies suggested that the majority of female entrepreneurs do not enter maledominated fields (Moore, 1990; Scherer, Brodzinski, \& Wiebe, 1990).

Most of the women described occurrences of discouragement and pernicious behavior toward them because of their gender; however, these women did not allow these negative experiences to cause them to waver in their ambitious pursuits. Many of the women spoke of the negative experiences as having a propelling affect on them professionally. They worked harder in order to prove their naysayers wrong. The existing literature regarding negative experiences of females in male-dominated fields focused on discussions of the negative impacts those experiences had on the females studied (Chu, 2005; Frieze \& Olson, 1994; Peng \& Jaffe, 1979; Steele, James, \& Barnett, 2002). The current study adds to the literature by identifying that discouragement and pernicious behavior experienced by females in male-dominated fields can be motivational tools for unwaveringly ambitious females.

The women were and are the first or only females in many aspects of architectural practice, education, and administration. Additionally, the women faced obstacles head on, and they used the obstacles as motivation.

In summary, this study supports the findings of the studies on the first females in male-dominated fields (Aldridge, 1994; Bagilhole, 2003; Rose, 1996) that indicated that these women are pioneering and change agents in organizational structure and culture. Additionally, the findings of this study identified a new, emerging theoretical construct that requires characterizing pioneering women in male-dominated fields differently than females in existing leadership theories. In sum, the women in this study maintained a focus on individual, professional success as they sought career advancement; however, they employ a leadership style that emphasizes shared learning and social networks of influence after they achieve that advancement.

\subsection{Recommendations for females who desire a similar career}

The findings of this study indicate that females who wish to pursue similar career paths should seek to experience early career exploration, earn Master's degrees from accredited colleges or universities, become an entrepreneur and principal of an architectural practice, and should be ready to endure and even thrive from the discouragement and obstacles that are still inevitable.
The findings of the current study proposed a new, emerging potential construct that requires that pioneering female leaders in male-dominated fields be characterized differently than female leaders in other contexts. This potential construct should be explored. This research was limited to 10 women administrators in architecture programs; therefore, a study that incorporates women who administrate in various other male-dominated professions would provide a broad view of how these women achieved their levels of success.

\section{REFERENCES}

Aldridge, A. 1994. Women priests: From exclusion to accommodation. British Journal of Sociology, 45(3), 501-510.

Almanac of Architecture and Design. 2004. Washington, D.C.: Greenway Communications. April 26, 2005 from http://www.aauw.org/laf/library/tenure stats.cfm

American Association of University Women. 2004. Tenure statistics. Retrieved April 26, 2005 from http://www.aauw.org/laf/library/tenure stats.cfm

Anthony, K. 2001. Designing for diversity: gender, race, and ethnicity in the architectural profession. Urbana, IL: University of Illinois Press.

American Institute of Architects. 2006. Homepage. Retrieved May 5, 2006 from www.aia.org

Bagilhole, B. 2003. Prospects for change? Structural, cultural and action dimensions of the careers of pioneer women priests in the Church of England. Gender, Work and Organization, 10(3), 361-377.

Brainard, S. G., Metz, S. S., \& Gillmore, G. M. 1999. WEPAN pilot climate survey: Exploring the environment for undergraduate engineering students. Paper presented at the meeting of the Institute of Electrical and Electronics Engineers Conference on women and technology.

Burstyn, J. 1980. Historical perspectives on women in educational leadership. In S.K. Biklen \& M. Brannigan (Eds.), Women and educational leadership (pp.65-75). Lexington, MA: Lexington Books.

Chaganti, R. 1986. Management in women-owned enterprises. Journal of Small Business Management, 24(4), 18-30.

Chu, I. 2005. Toward being a female engineer: women's experience in a male-dominated field. Proceedings of the American Sociological Association, 2005 Annual Meeting, USA, 1-19.

\subsection{Recommendations for future research}


Cohen, A. M. 1998. The shaping of American higher education: Emergence and growth of the contemporary system. San Francisco, CA: Jossey-Bass.

Creswell, J. W. 1994. Research design: Qualitative and quantitative approaches. Thousand Oaks, CA: Sage. Creswell, J. W. 2003. Research design: Qualitative, quantitative, and mixed methods approaches. Thousand Oaks, CA: Sage.

Deutschle, S. 2003, October 3. Female architects a rare breed, despite advances [Electronic version]. Columbus Business First. Retrieved May 3, 2006 from http://columbus.bizjournals.com/Columbus/stories/2003 110/06/focus7.htm

DiBrito, C., Carpenter, S., \& DiBrito, W. 1986. Women in leadership and management: Review of the literature 1985 update. NASPA Journal 23(3), 22-31.

Dietsch, D. 1991. Why an issue on women architects? Architecture, 13, 38.

Dreher, G. 2003. Breaking the glass ceiling: The effects of sex ratios and work-life programs on female leadership at the top. Human Relations, (56)5, 541562.

Eagly, A., \& Johannesen-Schmidt, M. 2001. The leadership styles of women and men. Journal of Social Issues, 57(4), 781-798.

Fletcher, J. 2004. The paradox of post-heroic leadership: An essay on gender, power, and transformational change. The Leadership Quarterly, 15, 647-661.

Frieze, I., \& Olson, J. 1994. Understanding the characteristics and experience of women in male- and female-dominated fields. In Stevenson, M. (Ed.) Gender Roles through the Life Span. Muncie, IN: Ball State University.

Funk, C. 1988, May. Career paths and working patterns of women in mid-management roles in business and education. Paper presented at the Women and Work Conference, Arlington, TX.

Gilligan, C. 1982. In a different voice. Cambridge: Harvard University Press.

Gregory, A. 2006. Identifying obstacles to professional achievement affecting women in architecture, and to determine the causes of high attrition rates in South Carolina. Unpublished master's thesis, Clemson University, Clemson, South Carolina.

Groat, L., \& Ahrentzen, S. 1997. Voices for change in architectural education: Seven facets of transformation from the perspectives of faculty women. Journal of Architectural Education, 50(4), 271-285.
Jablonski, M. 2000. The leadership challenge for women college presidents.

In J. Glazer-Raymo, B. K. Townsend, \& B. RopersHuilman (Eds.), Women in higher education: A feminist perspective.

Jagacinski, C. M. 1987. Androgyny in a maledominated field: The relationship of sex-typed traits to performance and satisfaction in engineering. Sex Roles, 17(9/10), 529-547.

Kaplin, W., \& Lee, B. 1995. The law of higher education (3rd Ed.). San Francisco, CA: Jossey-Bass.

Landecker, H. 1991. Why aren't more women teaching architecture? Architecture, 13, 23-25.

Leedy, P., \& Ormrod, J. 1997. Practical research: Planning and design. Upper Saddle River, NJ: Merrill Prentice Hall.

Lemkau, J. P. 1983. Women in male-dominated professions: Distinguishing personality and background characteristics. Psychology of Women Quarterly, 8(2), 144-165.

Marshall, C., \& Rossman, G. 1989. Designing qualitative research. Newbury Park, CA: Sage.

Merriam, S. 2001. Qualitative research and case study applications in education. San Francisco: Jossey-Bass.

Miller, J. 1986. Toward a new psychology of women. Boston: Beacon Press.

Morgan, L. 1986. Leadership and managerial styles of top-level women administrators in four-year institutions of higher education. Unpublished doctoral dissertation, University of Pittsburgh, Pennsylvania.

Moore, D. P. 1990. An examination of present research on the female entrepreneur - suggested research strategies for the 1990s. Journal of Business Ethics, 9(4-5), 275-281.

National Architecture Accrediting Board. 2006. Homepage. Retrieved May 3, 2006 from www.naab.org National Center for Education Statistics. 2005. Earned degrees in architecture. Retrieved August 30, 2006 from http://nces.ed.gov/programs/digest/d04/tables/dt 04_275.asp

Peng, S. S., \& Jaffe, J. 1979. Women who enter maledominated fields of study in higher education. American Educational Research Journal, 16(3), 285-293.

Ridgeway, C. 2001. Gender, status, and leadership. Journal of Social Issues, 57(4), 637-656. 
Rose, J. 1996. What difference is women's priesthood making to the Church of England? In Wakeman, $\mathrm{H}$. (Ed.). Women priests: The first years. London: DLT.

Rudman, L., \& Glick, P. 2001. Prescriptive gender stereotypes and backlash toward agentic women. Journal of Social Issues, 57(4), 743-763.

Scherer, R. F., Brodzinski, J. D., \& Wiebe, F. A. 1990. Entrepreneur career selection and gender: A socialization approach. Journal of Small Business Management, 28(2), 37-45.

Seymour, E., \& Hewitt, N. M. 1997. Talking about leaving: Why undergraduates leave the sciences. Boulder, CO: Westview Press.

Smallwood, S. 2001. Thorny tenure case at Case Western leads to sex-bias charges. The Chronicle of Higher Education, 47, 24.

Solomon, N. 1991. Women in corporate firms: The top positions in large offices aren't just for men anymore. Architecture, 13, 79.

Steele, J., James, J. B., \& Barnett, R. C. 2002. Learning in a man's world: Examining the perceptions of undergraduate women in male-dominated academic areas. Psychology of Women Quarterly, 26, 46-50.
Stevenson, M. (Ed.). 1994. Gender roles through the life span: a multidisciplinary perspective. Muncie, IN: Ball State University.

Tesch, R. 1990. Qualitative research: Analysis types and software tools. New York: Falmer.

Williams, J. 2004. Hitting the maternal wall [Electronic version]. Academe, 90. Retrieved April 26, 2005 from http://www.aaup.org/publications/Academe/2004/04nd/ 04ndwill.htm

Wilson, R. 2004, October 29. Report shows difficulty of sex-discrimination lawsuits [Electronic version]. The Chronicle of Higher Education, p.12.

Retrieved April 26, 2005 from http://sys.lib.clemson. edu:2052/universe/document? m=6ae8fcf0583e4d0adf $\mathrm{d} 4 \mathrm{f58943fff93e \&} \mathrm{docnum=6 \& wchp=dGLbVzb-}$ zSkVA\& md5=fc863171166e1d58cb4e33fecad852d5

Yin, R. 1989. Case study research: Design and methods. Newbury Park, CA: Sage. 